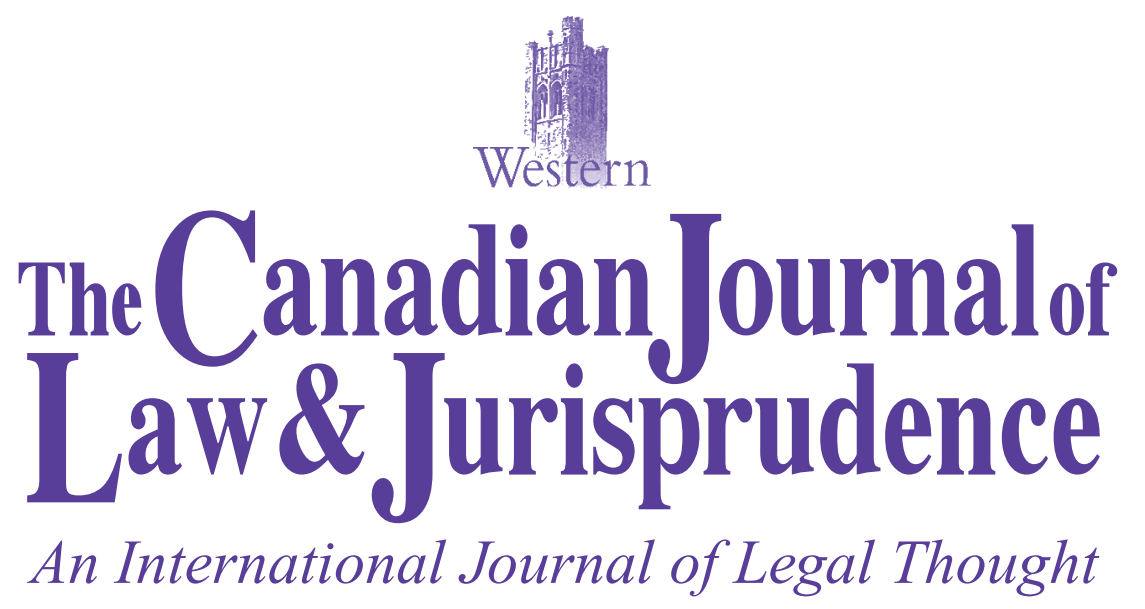

Editor: Richard Bronaugh

Bryan Druzin

Julen Etxabe

Ronit Donyets

Kedar

Charles-Maxime

Panaccio

George Pavlakos

Douglas Sanderson

Prince Saprai

Hamish Stewart

Discussion

Ian Bartrum
Law, Selfishness, and Signals:

An Expansion of Posner's Signaling Theory of Social Norms

Tragic Incommensurability and

Legal Judgment

The Unrecognized Dominance of Law in Morality: The Case of Promises

In Defence of Two-Step Balancing and Proportionality in Rights Adjudication

Constitutional Rights, Balancing and the Structure of Autonomy

Against Supersession

Weinrib on Unjust Enrichment

The Limits of Consent and the Law of Assault

Thoughts on the Divergence of Contract and Promise 
The Canadian Journal of LAW And JuRisprudence is published biannually. Appreciation is expressed to SSHRC for the aid to scholarly journals we receive. Articles may be sent by e-mail attachment, preferably in Word, to: CJLJeds@uwo.ca or by ordinary mail to The Editor, Canadian Journal of Law and Jurisprudence, Faculty of Law, UWO, London ON, Canada N6A 3K7. Authors are asked not to send their document "prepared for blind review" or in PDF. Footnotes should conform to the Canadian Guide to Uniform Legal Citation, 7th ed. Authors will receive 10 offprints (additional offprints are available at cost) and a free copy of the issue in which their article appears. Authors will hold the copyright in the text of their article while the Journal holds copyright in the format in which the article appears in the Journal and has the right of first publication and distribution of the article in that format.

Abstracts of articles are available at our Web Page: http://www.law.uwo.ca/faculty_staff/cjlj.html

ANNUAL SUBSCRIPTION (two issues), including postage and handling: Individuals

$\$ 62.60 \mathrm{CAD}+$ tax in Canada

$\$ 69.15 \mathrm{CAD} / \mathrm{USD}$ to USA

$\$ 74.90 \mathrm{CAD} / \mathrm{USD}$ to Rest of World

Institutions

$$
\begin{aligned}
& \$ 108.95 \mathrm{CAD}+\text { tax in Canada } \\
& \$ 115.50 \mathrm{CAD} / \mathrm{USD} \text { to USA } \\
& \$ 121.25 \mathrm{CAD} / \mathrm{USD} \text { to Rest of World }
\end{aligned}
$$

Single copies from the current volume and four years prior cost half the annual subscription price. Older back issues may be purchased, subject to availability, at a substantial discount off the regular price, plus postage $(\$ 8.50 /$ issue in Canada, $\$ 11.75$ /issue to USA, $\$ 14.75$ /issue to Rest of World).

Invoices are mailed annually with the January issue, but prepayment is also accepted. Cancellations must be received by December 31. Information concerning back issues and subscriptions, as well as new orders, may be secured from Tigger Jourard, Business Manager, CJLJ, Faculty of Law, UWO, London ON, Canada N6A 3K7. Phone: (519) 661-2111, ext. 88406. Fax: (519) 661-3790. E-mail: CJLJ@uwo.ca 


\section{J.}

\section{TABLE OF CONTENTS}

Bryan Druzin

Julen Etxabe

Ronit Donyets Kedar

Charles-Maxime

Panaccio

George Pavlakos

Douglas Sanderson

Prince Saprai

Hamish Stewart

Discussion

Ian Bartrum
Law, Selfishness, and Signals:

An Expansion of Posner's Signaling

Theory of Social Norms 5

Tragic Incommensurability and

Legal Judgment

The Unrecognized Dominance of Law

in Morality: The Case of Promises

In Defence of Two-Step Balancing and

Proportionality in Rights Adjudication

Constitutional Rights, Balancing and the Structure of Autonomy

Against Supersession 155

Weinrib on Unjust Enrichment 183

The Limits of Consent and the

Law of Assault .205

Thoughts on the Divergence of Contract and Promise

Faculty of Law

The University of Western Ontario

London, Ontario

Canada 


\title{
In Defence of Two-Step Balancing and Proportionality in Rights Adjudication
}

\author{
Charles-Maxime Panaccio
}

\section{Introduction}

Two-step proportionality/balancing (TSPB, for short) has become the standard method for human rights decision-making. Typically, it has taken root in statutory, constitutional, supra-constitutional and international rights regimes which contain both (1) rights-conferring provisions and (2) limitations clauses which state that the rights conferred by the rights-provisions can be limited for various more or less general reasons. ${ }^{1}$ This drafting structure is taken as a cue by decision-makers (courts, generally) to develop a two-step method of decision-making: the first step consists in determining whether a rights-provision has been infringed/limited; and if the answer to that first question is positive, the second step consists in determining whether the infringement/limit is reasonable or justified according to test of proportionality.

Unsurprisingly, in light of its popularity, TSPB has been the regular target of some criticism - notably quite recently in this very journal. ${ }^{2}$ Opponents have attacked both its two-step aspect and its use of proportionality-balancing. Against the two-step aspect, they often argue that fragmenting the decision-making process distorts moral reality by suggesting that rights are routinely being infringed/violated, whereas it is only once the limitations clause has been applied and the all things considered reasoning completed that we can truly say that the 'rights' question ('is

Sincere thanks to Giovanni Battista Ratti for guidance on the topic of defeasibility and to Wayne Sumner and Matthew Lewans for detailed and helpful comments.

1. For instance, this structure characterizes constitutional doctrines in Canada, Germany, South Africa and Israel. It is also found in the application of statutory Bills of Rights in the United Kingdom, New Zealand and Australia and in the application of international rights instruments such as the Universal Declaration of Human Rights, the Convention for the Protection of Human Rights and Fundamental Freedoms (European Convention on Human Rights), the International Covenant on Civil and Political Rights and the International Covenant on Economic, Social and Cultural Rights. See Grégoire C.N. Webber, The Negotiable Constitution: On the Limitation of Rights (Cambridge: Cambridge University Press, 2009) at 55-64 [Webber Negotiable Constitution] and Alec Stone Sweet \& Jud Mathews, Proportionality Balancing and Global Constitutionalism (2008) 47 Colum. J. Transnat'1 L. 72, 97-152 [Stone Sweet \& Mathews Global Constitutionalism] for a more detailed overview and discussion.

2. Grégoire C.N. Webber, 'Proportionality, Balancing, and the Cult of Constitutional Rights Scholarship' (2010) 23 Can. J. L. \& Jur. 179 [Webber Cult]; Webber Negotiable Constitution, supra note 1, esp. c. 2-4; Bradley W. Miller, 'Justification and Rights Limitations' in Grant Huscroft, ed., Expounding the Constitution: Essays in Constitutional Theory (New York: Cambridge University Press 2008) 93 [Miller]; Norman Siebrasse, 'The Oakes Test: An Old Ghost Impeding Bold New Initiatives'(1991) 23 Ottawa L.Rev. 99 [Siebrasse]; Pierre Blache, 'The Criteria of Justification under Oakes: Too Much Severity Generated Through Formalism' (1991) 20 Man. L.J. 437 [Blache]; Errol P. Mendes, 'In Search of a Theory of Social Justice: The Supreme Court Reconceives the Oakes Test'(1990) 24 R.J.T. 1 at 3, 6 [Mendes]; Pamela A. Chapman, 'The Politics of Judging: Section 1 of the Charter of Rights and Freedoms' (1986) 24 Osgoode Hall L.J. 867 [Chapman]. 
there a right or not?') has been answered. This wrong-headed multiplication of rights-infringements/violations would eventually lead to either the overvaluation or the devaluation (or both) of the currency of rights and 'impoverish moral discourse.' Against proportionality-balancing, opponents charge that 'proportionalitytalk' is empty and tends to mask the nature of the task at hand by suggesting that it is mechanical-technical rather than moral-political.

This article seeks to defend TSPB against these arguments and to depict it in a more appropriate and favourable light. Hence, it is first argued that opponents' arguments, although sometimes theoretically instructive, do not really sting. More precisely, it is argued that the 'fragmentation of reasoning' and proportionalitytalk simply do not have the dire moral consequences that opponents suggest they have. Second, it is argued that TSPB constitutes a framework for public argumentation and authoritative decision-making in a context where a question of legal/moral/practical reasoning (i.e., has a right/duty been violated by government?) is raised. More specifically, it is argued that in such circumstances TSPB naturally and usefully uses notions associated with adversarial argumentative structures and authoritative decision-making institutions, namely burdens, presumptions and prima facie/defeasible propositions. Moreover, it is argued that given the context of its application, the method for practical reasoning deployed by TSPB-revolving around the notion of proportionality - is appropriate in its simplicity and limited moral commitments.

\section{An Example: The Canadian Charter}

There are various ways of drafting a rights-document, but it has become standard to include a list of rights, either general (e.g., a right to freedom of expression) or qualified (e.g., a right against unreasonable searches or seizures), and to include as well one or many provisions which state that these rights are not absolute and may be limited when reasonable or justified. These limitations-justification provisions may be drafted more or less generally, as they may generally require that limits be justified or that the justification be able to fit a more particular description (public order/morals, health, safety, the rights of others, etc.). For instance, in Canada, the Charter's sections 2 to 23 distribute rights and, as is well known, section 1 provides that these rights are guaranteed 'subject only to such reasonable limits prescribed by law as can be demonstrably justified in a free and democratic society. ${ }^{3}$ On the other hand, the European Convention on Human Rights tends to be more specific by providing that limits to certain rights must be justified by considerations related to public safety, public order, health or morals or the protection of the rights and freedoms of others. ${ }^{4}$ But despite variances in the generality of heads of justification, 'rights and limits drafting structures' have naturally led to two-step decision-making methods. For example, at least since the Supreme

3. Canadian Charter of Rights and Freedoms, Part I of the Constitution Act, 1982, being Schedule B to the Canada Act 1982 (U.K.), 1982, c. 11.

4. Convention for the protection of Human Rights and Fundamental Freedoms, 4 November 1950, 213 U.N.T.S. 221 at 223, Eur. T.S. 5 [ECHR]. For instance: art. 8-11. 
Court of Canada's decision in R. v. Oakes, ${ }^{5}$ section 1 has consistently been interpreted as mandating a two-step analysis: first, the court determines whether one of the Charter 'rights-provisions' has been infringed by public authorities. If that is the case, the court must then determine whether the infringement constitutes a reasonable/justified limit to the right. From the first step to the second, the burden of proof shifts from the plaintiff to the government.

Therefore, at the first stage of a rights-analysis, courts typically determine whether the normative conditions flowing from a given right-provision (conditions which have been established by courts themselves) have been met. For example, s. 2(b) of the Charter confers on everyone the right to freedom of expression. In principle, for s. 2(b) to be infringed, a finite set of conditions have to be met. It has to be the case that the government's action has interfered, in its object or effect, with the non-physically violent conveyance of meaning. If the direct object of the government's measure was to interfere with the transmission of meaning, there is an infringement of s. 2(b). However, if the measure interferes with the transmission of meaning only through its effects, then it has to be shown that the specific message interfered with has some relation with the values promoted by the protection of freedom of expression - i.e., the search for truth, democracy/self-government and personal fulfilment. ${ }^{6}$ While these conditions are quite simple, it gets slightly more complicated when courts are dealing with what are sometimes called 'qualified rights,' such as the right not to have one's life, liberty or security of the person interfered with save in accordance with the principles of fundamental justice, which is conferred by s. 7 of the Canadian Charter. Then the first step may comprise additional sub-steps.

Be that as it may, if it is concluded that there is an infringement of the rightprovision related conditions, then courts move on to the second step, which consists in the application of a proportionality-balancing test. In Canada, the test consists of two essential criteria. First, the state's objective(s) must be sufficiently important. Second, the means chosen must be proportional. The latter 'proportionality of means analysis' has three components: (1) 'Rational Connection' (2) 'Minimal Impairment' and (3) 'General Proportionality.' Of course, the proportionality analysis may vary slightly in form and application amongst jurisdictions. For instance, in South Africa the analysis is not necessarily done in a more formal 'sequence of discrete steps. ${ }^{8}$ And whereas in Canada courts tend to impugn legislation for a lack of 'Minimal Impairment,' courts in Germany and Israel tend to be more willing to do so solely on the basis of an absence of General Proportionality. ${ }^{9}$ Keeping

5. R. v. Oakes, [1986] 1 S.C.R. 103 [Oakes].

6. Irwin Toy Ltd. v. Quebec (Attorney general), [1989] 1 S.C.R. 927.

7. In Robert Alexy's seminal proportionality theory of constitutional rights, these components are respectively called 'suitability,' 'necessity' and 'the Law of Balancing.' Robert Alexy, A Theory of Constitutional Rights, trans. by Julian Rivers (Oxford: Oxford University Press, 2002) 397414. See also Webber Negotiable Constitution, supra note 1 at 70-79.

8. Stone Sweet \& Mathews Global Constitutionalism, supra note 1 at 127, 129, 163-64.

9. Dieter Grimm, 'Proportionality in Canadian and German Constitutional Jurisprudence' (2007) 57 U.T.L.J. 383 at 389, 393 [Grimm]; Stone Sweet \& Mathews Global Constitutionalism, ibid. at 163. 
the possibility of variations in mind, then the Canadian version of TSPB can quite safely be used as a model for the others. ${ }^{10}$

The 'Rational Connection' component of proportionality can be read in different ways (and has been by the Supreme Court of Canada). In its least demanding form, it requires that the rule be causally able to achieve the accepted objective. Call this 'the minimal instrumental rationality version' of Rational Connection. ${ }^{11}$ Obviously, this version is usually easily met by the state because only absurdly irrational laws would fail it. It is indeed difficult to imagine a rule which is thoroughly incapable of achieving its valid underlying objective. Of course such rules, being not only instrumentally irrational, but also necessarily blatantly disproportionate in terms of balance of reasons, should not be kept on the books. But they tend to never enter them. Actual rules may have side-effects, even in terms of sabotaging their own objectives to some extent, but they are almost never completely causally deficient or completely self-defeating. Rational Connection could thus be described, to borrow the colourful words of Felix Cohen, as asking courts to act as 'lunacy commissions sitting in judgment upon the mental capacity of legislators. ${ }^{12}$ Nevertheless, it enables courts to pay attention and establish the weight of the 'public side of the balance,' so to speak, which may not be superfluous in terms of institutional relations between the judiciary and other branches of government. ${ }^{13}$ At worse, while perhaps practically useless, the minimal version of Rational Connection is harmless.

In its more demanding forms, Rational Connection requires more extensive moral balancing. This reflects a broader understanding of reason (or rationality), according to which a reasonable or justified action is also one which the balance of reasons favours over alternatives. Hence, when a rule is not even able to achieve its purported objectives, it is instrumentally irrational. But when a rule has disproportionately large deleterious implications, it can also be said to be irrational (or unreasonable) in the sense that it defies the balance of reasons. ${ }^{14}$ In the most recent case concerned with the application of $s$. 1 , however, every judge on the

10. It has in fact been used as a model by some of the other jurisdictions, e.g., in South Africa, Israel, Ireland and New Zealand. Stone Sweet \& Mathews Global Constitutionalism, ibid. at 123-34, $125,133,135$.

11. Instrumental rationality being one particular type of rationality. Philosophers have been arguing for a long time as to whether one can be instrumentally rational and yet irrational, for instance by failing to have appropriate desires or beliefs, or by failing to act morally or according to the balance of applicable reasons. Another way to put the issue is to ask whether someone who is acting immorally but in accordance with instrumental rationality can be said to be acting rationally at all. Thankfully, for the present purposes, I do not need to express any views in this debate and it shall suffice to raise the different notions of reason and rationality at play. For a useful overview of the various meanings of rationality, see Steven Lukes, 'Some Problems About Rationality' in Bryan R. Wilson, Rationality (New York: Harper \& Row, 1970).

12. Lucy Kramer Cohen, ed., The Legal Conscience: Selected Papers of Felix S. Cohen (New Haven, CT: Yale University Press, 1960) at 44.

13. This point is made in Stone Sweet \& Mathews Global Constitutionalism, supra note 1 at 89 , 163-64.

14. Here the rational action is the morally right action. Morally wrong action implies some form of irrationality. A well-known exposition of such a view can be found in K. Baier, The Moral Point of View: A Rational Basis of Ethics (Ithaca, NY: Cornell University Press, 1958). See also J. Raz, 'Explaining Normativity: On Rationality and the Justification of Reason' in Engaging Reason: On the Theory of Value and Action (Oxford: Oxford University Press, 1999) 67. 
Supreme Court of Canada chose to favour the minimal instrumental version over the fuller balancing version. ${ }^{15}$ This also seems to be the version generally favoured in other jurisdictions. ${ }^{16}$

If it is concluded that the state's rule is rationally connected to the objectives, courts must then consider whether the rule impairs the right as little as possible. This is the 'Minimal Impairment' component of proportionality tests. It is in fact a prescription to minimize the (negative) 'right-affecting,' side-effects of action. In other words, some relative disvalue presumptively flows from a conclusion that the conditions associated with a rights-provision have been violated; this disvalue should be avoided as much as possible, since it is in accordance with the balance of reasons to do so. In short, if the state can achieve its objectives without affecting right-related values to the same extent, then the balance of reasons points towards adopting that alternative path.

Strictly speaking, Minimal Impairment entails that the government is deemed to be justified in wanting to maximize the attainment of its objective. If a less impairing solution were to jeopardize the realization of the objective to whatever extent, the government would, in principle, satisfy this part of the proportionality test. Thus, again strictly speaking, this is not a full-fledged assessment of proportionality. Rather, it is a truncated assessment, as no full evaluation and balancing of positives and negatives is involved. ${ }^{17}$ What is to be determined is whether the same positives could be achieved with less of the negative. And, following this purified version of Minimal Impairment, if that proves impossible, then the state's action would not (yet) have been shown to be unjustified. ${ }^{18}$ Therefore, if this version of Minimal Impairment were to be applied strictly, it should not be overly difficult to satisfy.

Even if the state meets the Rational Connection and Minimal Impairment components of proportionality tests, for a rule to be justified, there must also be proportionality between, on the one hand, the objective and beneficial effects of the legislation, and, on the other, its deleterious effects. In other words, a general balancing of reasons must favour the impugned law over any alternative. Call this last component of the proportionality test 'General Proportionality.' Again, this is the only requirement which is, strictly speaking, a full assessment of proportionality. ${ }^{19}$ Therefore, it could be expected that truly controversial cases should almost always

15. Alberta v. Hutterian Bretheren of Wilson Colony, [2009] 2 S.C.R. 567 at paras 48, 51.

16. Stone Sweet \& Mathews Global Constitutionalism, supra note 1 at 75. A. Barak, 'Proportional Effect: The Israeli Experience' (2007) U.T.L.J. 369 [Barak] at 372-73; Grimm supra note 9 at 389.

17. Barak, ibid. at 373-74; Grimm, ibid. at 393.

18. It is that stripped down version of Minimal Impairment that was favoured (with some qualifications) by the majority in Hutterian Brothers, supra note 15 at para. 54-55.

19. The same point is made even more effectively by L.W. Sumner in The Hateful and the Obscene: Studies in the Limits of Free Expression (Toronto, ON: University of Toronto Press, 2004) [Sumner] at 66-67. See also Barak, supra note 16 at 374, 380-81. Grimm, supra note 9 at 39394, 396; Alan Brudner, 'What Theory of Rights Best Explains the Oakes Test?' in Luc B. Tremblay \& Grégoire C.N. Webber, eds., La limitation des droits de la Charte: essais critiques sur l'arrêt R. c. Oakes/The limitation of charter rights: critical essays on R. v. Oakes (Montreal, PQ: Thémis, 2009), 59 at 60 [Tremblay \& Webber]; Blache, supra note 2 at 444. 
be settled at that stage. Yet, some courts seem to prefer to rule against the government on the grounds of failure to meet Minimal Impairment, in order to avoid ruling solely on the basis of Overall Proportionality. One plausible hypothesis is that Minimal Impairment seems to leave government objectives untouched, and thus seems less grounded in controversial evaluative disagreements. The tendency of some courts to inflate the range of Minimal Impairment may therefore at least partly be explained by considerations of institutional legitimacy. Hence, deciding controversial cases on the basis of Minimal Impairment has clear rhetorical benefits, but it comes at the price of a certain kind of self-deception. ${ }^{20}$

\section{Critiques}

There are essentially two lines of criticism aimed at TSPB: one is aimed at the fragmentation of the reasoning created by the two steps and the other is aimed at 'proportionality-discourse.'

It has thus been observed that the sharp analytical distinction between determining the scope of a right and determining whether its infringement is justified will sometimes transform what may be at most a simple prima facie violation of a moral right into a full-fledged one. Indeed, an actual moral right will only have been infringed if it is rightly concluded that the infringement of a rights provision (i.e., a limit to a right) was not justified all things considered. Thus, there is a risk of overvaluing a conclusion that right-provision-conditions have been infringed by thinking that an actual moral right has been violated while that is really not the case. At the same time, under TSPB justified infringements of rights are quite common and, as a consequence, rights cannot be seen as special moral considerations after all. Rather, rights are relegated to the status of mere defeasible reasons. In sum, the parcelling of the reasoning creates a risk of devaluation for the currency of true rights, because rights are wrongly but consistently being conceived as something expendable. This would impoverish political and moral discourse and threaten the level of respect afforded to true moral rights. ${ }^{21}$

As for proportionality, discomfort has regularly been expressed with respect to the notion's substantive emptiness and 'manipulability. ${ }^{22}$ Also, it has been argued that the discourse of proportionality claims an accuracy that does not obtain and that this would help camouflage what really happens in rights reasoning. In other words, the discourse of proportionality would transform intrinsically moral-political debates about the scope and content of rights into formal-technical claims of weight and balance, which would in turn lead to the depoliticization and de-moralization

20. Grimm, supra note 9 at 395. For a similar observation see David M. Beatty, The Ultimate Rule of Law (Oxford: Oxford University Press, 2004) at 163 [Beatty]; Siebrasse, supra note 2 at 118. I am naturally drawn towards an attitude which tackles controversy head on as opposed to one which sweeps part of it under the rug, but a judge may retort that such an attitude is easier for an academic to adopt.

21. Webber Negotiable Constitution, supra note 1 at 5, 115, 121-23, 139; Webber Cult, supra note 2 at 201-02; Miller, supra note 2 at 95-96, 115; Siebrasse, supra note 2 at 118-19.

22. For instance, Chapman, supra note 2; Mendes, supra note 2 at 3; Siebrasse, supra note 2 at 101-02. 
of rights. ${ }^{23}$ Finally, it has also been suggested that proportionality-talk assumes the commensurability of values and/or action-options, and therefore fails to acknowledge the reality of incommensurability in morality/practical reasoning. ${ }^{24}$

It has therefore been argued that TSPB should be abandoned and replaced with a method that better coheres with a commitment to rights' 'specialness' and which enables a more explicit struggle with the moral reasoning inherent to rights-determination. ${ }^{25}$ Limitations to rights should thus be conceived not as limits, infringements or violations, but as specifications of the content and scope of rights. More precisely, rights should be conceived as conclusions to an exercise in practical reasoning that takes into account not only the interest, value or principle grounding the right, but also all other countervailing moral considerations. In other words, infringements/violations of rights would not be ascertained until the boundary of the right has been specified through an all things considered exercise in practical reasoning. ${ }^{26}$

\section{Deflection}

\section{A. Fragmentation of the Reasoning and Moral Loss}

Part of the argument against fragmentation recently put forward by both Webber and Miller seems to boil down to this: TSPB actually reduces rights to defeasible premises; this clashes with the usual status afforded to rights in morality, which will cause (or is likely to cause) moral confusion and moral mistakes (because statements of rights will either be over-valued or under-valued, or both). This argument seems simple enough, but let us parse its logic further. First, of course, there can be no quarrel with the proposition that in the Charter context 'rights-provisioninfringements/violations' (often referred to as 'rights-infringements' tout court, because, obviously, the rights-provisions purport to grant rights, so if the provision is infringed, it is understandable that one is tempted to say that the right conferred per se has been infringed) amount to defeasible premises.

Now, another premise of the argument is that true rights do have special status, a certain prestige, in the true moral world. What does that mean? It has to mean that Webber and Miller are working on the basis of a particular moral theory which gives pride of place to rights. This could be one of two things: either a rights-based theory, or a theory which is not rights-based but is compatible with rights statements being somehow important, conclusive, indefeasible. I think it is safe to say that rights-based moral theories are generally of deontological/Kantian descent. They give pride of place to certain rights because these rights, properly defined, reflect moral personhood. A proper deontological right thus carries substantial moral force

23. Webber Negotiable Constitution, supra note 1 at 6, 10, 89-90, 94, 96, 99-100, 104; Webber Cult, supra note 2 at 179, 191; Chapman, supra note 2; Siebrasse, supra note 2.

24. Webber Negotiable Constitution, supra note 1 at 90-100; Webber Cult, supra note 2 at 194-98.

25. Webber Negotiable Constitution, supra note 1 at 115-16, 118, 123, 126-27; Webber Cult, supra note 2 at180; Siebrasse, supra note 2; Mendes, supra note 2; Chapman, supra note 2.

26. Webber Negotiable Constitution, supra note 1 at 6, 10, 116-17; Blache, supra note 2, 438-39; Siebrasse, supra note 2 at 119. 
against other countervailing moral considerations, sometimes other rights, sometimes utility or other interests or values. Those details are irrelevant for our purposes, however, because I do not think that either Miller or Webber are working with a deontological/rights-based theory. Webber does invoke deontologicallyinspired philosophers to support the assertion that rights are necessarily important, ${ }^{27}$ but in his own theory of rights, the importance of rights resides in their being conclusory of an exercise in practical reasoning (which also makes them absolute). Miller also seems to adopt the view that rights are typically absolute, and would probably be comfortable with Webber's view of rights, as long as the interests of the political community are properly taken into account in the 'all things considered' calculus that leads to the determination of the rights-issue. ${ }^{28}$

According to Webber and Miller, the Charter's fragmentation of reasoning creates the danger that the appropriate notion of rights as conclusory absolutes will be confused with the defeasible one of charter right-provision infringement. This may lead to people giving exaggerated (absolute or quasi-absolute) importance to those merely defeasible prima facie claims. ${ }^{29}$ Webber adds a complication to this speculation by suggesting that this may lead to people believing that rights are actually merely defeasible propositions. In that case people could come to consider true conclusive rights-propositions to be defeasible, which would erode respect for true rights. ${ }^{30}$ So there are in fact three possible consequences to the 'rights-imposture' caused by fragmentation: either rights will be inappropriately inflated, or they will be inappropriately demeaned; or both, since some may think that rights are more important than they are and some may think that rights are less important than they are. Either way, the argument is that this will lead to moral mistakes being made (either by public institutions or individuals).

The problem with these arguments is that they diagnose a problem which is either inexistent or easily cured (which would then make it inexistent). First, the problem is very possibly inexistent. That is, for their argument to work, Webber and Miller have to show that the feared confusion and moral consequences are real or at least probable. But I am afraid that they are unable to do this. Whether constitutional doctrine has caused moral confusion and mistakes is unverifiable, of course, but it really does not seem that a critical mass of people have been deceived in their moral outlook and reasoning by a constitution-related confusion between prima facie rights and conclusory rights. Rather, it is much more likely that people have been applying the same moral outlook as to the general issue of right/justification, even if charters of rights actually confer prima facie rights rather than true rights. In other words, it is unlikely that constitutional doctrine and structure have lead people to make counterintuitive 'all things considered' moral decisions. It is quite likely that whatever labels are attributed to the infringement of rights-provisions, people (and judges) still proceed to a general exercise in moral balancing in any event, being aware of the fact that the interests/values protected by rights-provision

27. Webber Negotiable Constitution, supra note 1 at 116-17.

28. Ibid. at 6, 10, 116; Miller, supra note 2 at 95 and n 7.

29. Miller, ibid. at 96.

30. Webber Negotiable Constitution, supra note 1 at 121-22. 
sometimes prevail, sometimes not (as clearly suggested by the presence of limitations clauses). In other words, it is suggested that labels made very little to no actual moral difference and that the only consequence may have been epistemological. The evolution of the Supreme Court of Canada's views on section 1 is, I believe, confirmative of this 'no-difference thesis. ${ }^{31}$

But even if labels did make a moral difference, that problem could easily be cured by dispelling the confusion. Hence, it could simply be pointed out that rightprovisions infringements/violations are not infringements or violations of true rights; that true rights appear only once the 'all things considered' analysis has been completed. That being said, however, there is no avoiding the fact that charters of rights are charters of rights, and that at some point some right-provisions-related interests/values are going to have to be considered and balanced against countervailing interests/values. So you could avoid calling the infringement of rightprovisions-related interests or values 'infringements of rights,' but the 'all things considered'/conclusory right reasoning will still require at least two steps. Miller and Webber's point is thus ultimately a point about the possible moral consequences of linguistic usage, but they appear to vastly overestimate those moral consequences and/or to ignore that these consequences can easily be avoided by acknowledging that charters of rights are in fact charters of prima facie rights. The diagnosed problem is therefore either negligible or dissolves altogether. Moreover, as shall be argued below, there is an explanation and justification for the fragmentation effected by the two-step method: it usefully parcels the question of whether or not there is a true right into various elements, for the sake of argumentation and decision-making.

\section{B. Proportionality}

Recall that one argument put forward against TSPB is that it suggests a distorted view of constitutional rights decision-making by depicting it as a formal, technical — even mathematical—, as opposed to a moral, endeavour. But it remains hard to see how exactly proportionality-talk suggests that. In fact, it is hard to understand what is meant by 'technical' in that context. Who would ever literally assimilate constitutional rights decision-making to a mathematical or otherwise technicalformal endeavour? That would just be bizarre. Even the first interpreters of the Canadian Charter were aware of its political-moral nature. ${ }^{32}$ Hence, at least in

31. The (prima facie) rights-protective rhetoric of Oakes was quite quickly toned down in case such as R. v. Edwards Books and Art Ltd., [1986] 2 S.C.R. 713, esp. para. 147; United States of America v. Cotroni, [1989] 1 S.C.R. 1469 and R. v. Keegstra, [1990] 3 S.C.R. 697. In Keegstra at 735 , for instance, Chief Justice Dickson said:

The analytical framework of Oakes has been continually reaffirmed by this Court, yet it is dangerously misleading to conceive of s. 1 as a rigid and technical provision, offering nothing more than a last chance for the state to justify incursions into the realm of fundamental rights. From a crudely practical standpoint, Charter litigants sometimes may perceive s. 1 in this manner, but in the body of our nation's constitutional law it plays an immeasurably richer role, one of great magnitude and sophistication.

32. Federal Republic of Germany v. Rauca (1982), 38 O.R. (2d) 705 at 715, 717 (H.C.); R. v. Kehayes, [1982] N.S.J. No. 158 at para. 50 (Cty Ct) (QL). 
Canada, the idea that constitutional rights determination required a foray into political morality was out there, being publicly acknowledged by judges, from the very beginning. There has never been any 'formalist' or 'technocratic' conspiracy. To be sure, the suggestion that the concept of proportionality is substantively vacuous has some truth to it. It is substantively quite vacuous. Proportionality is not a value; rather, it is a relation between values. It thus requires independent values to be put to work. In other words, in a moral or practical reasoning context, proportionality requires a normative theory to breathe life into it, in addition to any 'empirical' analysis of the circumstances. Therefore, theories using proportionality as a fundamental building block are problematic as long as they pretend to render fundamental attributions of moral value unnecessary. But of those who have developed sophisticated theories around proportionality, only David Beatty seems to clearly make that mistake. ${ }^{33}$

If attribution of moral value is necessary, one may then be tempted to ask which moral-political theory should be selected. This would require a deep journey into normative ethics, a journey which is well beyond the scope of that paper or any court decision. Obviously, as hinted at by courts, the theory should be broadly liberal-democratic, but this is probably as far as they can practically go. In any event, once a more practical (as opposed to ontological) view of proportionality is takenwhich I submit is the sensible thing to do-it is easy to see that it is happily compatible with (focussing on the main normative families) both deontological and consequentialist-instrumentalist theories of morality. It is obviously compatible with the latter theories; but it would also be no stretch in the language to describe the infringement of a deontologically described individual interest as being 'disproportionate' (i.e., unjustified) when compared to the advantages obtained through its infringement. Be that as it may, in light of the fact that plenty of consequentialist theories make space for deontological-type concerns, a choice between these families of normative theories would most probably not lead to any differences in results in the vast majority of cases. I would also add that a practical view of proportionality can very easily accommodate theories of morality or practical reason which make space for the incommensurability or incomparability of values or action-options. ${ }^{34}$ Thus, a choice made (by a legislature or court) between two incommensurable or incomparable options can quite sensibly and intuitively be described as proportionate, and this, once again, will cause little or no moral loss whatsoever (the only real potential loss being epistemological). ${ }^{35}$

33. Beatty, supra note 19. However, Robert Alexy, the father of proportionality theory and Beatty's main source of inspiration, seems to acknowledge that value attribution is not displaced by proportionality analysis. See Alexy, supra note 7 at 100, 105, 366; see also, Mattias Kumm, 'Political Liberalism and the Structure of Rights: On The Place And Limits of the Proportionality Requirement' in George Pavlakos, ed., Law, Rights, Discourse: The Legal Philosophy of Robert Alexy (Oxford: Hart, 2007) 131.

34. For present purposes Raz's 'simple' definition of incommensurability should do: '[Action-options] $\mathrm{A}$ and $\mathrm{B}$ are incommensurate if it is neither true that one is better than the other nor true that they are of equal value'; see Joseph Raz, The Morality of Freedom (Oxford: Clarendon Press, 1986) at 322 .

35. See for instance the dissenting opinion of Justice Gonthier in Sauvé v. Canada (Chief Electoral Officer), [2002] 3 S.C.R. 519. 
It sometimes has seemed as if critiques of proportionality were actually asking for a complete theory of morality, value, or practical reasoning, which would provide a step by step recipe to unfailingly correct (constitutional) decision-making. ${ }^{36}$ Such requests are remarkably misplaced. First, because the decision-making method provided by courts is principally addressed to practicing lawyers and other judges, it has to be general, communicable, as well as workable. Second, and even more crucially, because although the decision-making process as to justification can be structured and streamlined, at some point, some judgment, some evaluation, is going to have to be made by no one else but the decision-maker. As Kurt Baier has said with respect to moral/practical reasoning:

Moral deliberation, like all kinds of deliberation, is a sort of calculus, a method of reckoning, of working out something - which course of action is supported by the best moral reasons. All that can be expected by moral philosophers is the clarification of the calculus, the statement of the general rules, and the methods of using them in particular calculations. It cannot be expected that philosophers should answer all moral questions or problems beforehand, or that, after the elucidation of this calculus, its users will find solving their problems much easier, or even that all problems will now be capable of solution. The procedure is much like weighing. One can only explain the weighing machine and check the weights: the weighing itself has still to be done on each particular occasion. ${ }^{37}$

It is therefore not surprising that the Supreme Court of Canada has limited itself to drawing the broad outlines of a liberal-democratic theory of political morality, mentioning values such as personal dignity, social justice and equality, pluralism and tolerance, respect for cultural and group identity, and democratic participation. ${ }^{38}$ There was really no other practicable way.

In sum, I do not think that the anti-TSPB arguments draw much blood. The most that can be said for the arguments against the fragmentation of the reasoning is that they suggest a useful theoretical distinction between the infringement of normative conditions associated with rights-provisions and the infringement of moral rights. As to arguments against proportionality, they seem to be reacting (partly rightly) to the exaggerated claims made by some proportionality theorists like Beatty or Alexy. But once these overblown claims are cut down to size, the use of proportionality can take its justified place as a heuristic tool for practical-moral reasoning. In sum, although the arguments put forward by critiques of TSPB are sobering, they do not seem at all to justify the suggestion that TSPB has any nonnegligible moral (as opposed to epistemological) consequences.

\section{Multi-Step Balancing as Formal Method of Argumentation and Practical Reasoning}

I now wish to put TSPB in what I submit is a more appropriate and favourable light. That is, I shall argue that one particularly illuminating way of looking at TSPB is

36. For instance: Mendes, supra note 2; Chapman, supra note 2; Siebrasse, supra note 2 at 131.

37. Baier, supra note 14 at 172.

38. Oakes, supra note 5 at 136. 
by conceiving it as a formal-legal method of practical reasoning. As such, TSPB's two steps are best explained and justified through the notions of presumptions, burdens, and prima facie/defeasible propositions. The usefulness of these steps is in their division of argumentative labour and parcelling of various opposing considerations. As to the proportionality test, it is best explained as a shallow/ normatively agnostic heuristics for practical reasoning.

\section{A. Burdens and Standards of Proof}

Burdens and standards of proof are rarely discussed in any depth in the constitutional rights context. Of course, the relevant case law typically states that some burden rests on the plaintiff as to the right-provision infringement issue, and on the government as to the all things considered justification issue; and that both infringement and justification have to be proved on a "balance of probabilities" standard. But we often gloss over what this really entails. What are those burdens which have been distributed, and when could the issues of burden and standard become relevant or determinative, if ever?

Burdens of proof determine which party to a case must prove which material facts to make its case. Standards of proof determine the level of proof required for a material fact to be considered as having occurred. In judicial settings, burdenrules play the role of uncertainty-breakers when the existence of a given material fact has not been proven in accordance with the applicable standard. The party on which the burden lies is deemed not to have proved that fact. Of course, some material facts do not have to be proved because they are considered to be so generally well-known that they can be judicially noticed. Courts also have to take judicial notice of most legal rules i.e., constitutional provisions, statutes, etc., and thus these rules and their contents do not have to be proved by the parties. But what does this mean in the context of constitutional rights decision-making?

First, it is necessary to establish what exactly needs to be proved by each party, i.e., what each party's burden is. We know that a plaintiff has to establish that the conditions associated with the infringement of a right-provision have been met. And we know that once this had been done, the government has the burden of establishing that its rule is reasonable and justified in a free and democratic society. That in turn translates into establishing that the rule is proportional. So a plaintiff has to show that it is more likely than not that a right-provision's conditions have been infringed, and the government has to show that it is more likely than not that its measure was proportional. These are what are often termed mixed questions of fact and law. One source of problems here is that constitutional norms are controversial. As such, they constitute moving targets. Hence, purely factual (including all kinds of social science and expert) evidence may be put forward by a plaintiff to show the gravity or extent of an infringement, or by the government to show the importance of a given objective or the pervasiveness of a given problem. But fundamentally, the question 'has plaintiff/government met the standard (the balance of probabilities)' is inextricably linked to a moral evaluation of the relative importance of the rights-related and objective-related values. So it may be said that the evidence 
can help with the calculus, notably by shedding light on elements of a situation which should be considered relevant, but it will never help fix the initial and most fundamental attribution of value. That is, although facts are undoubtedly relevant to their determination, 'right-provision infringement' (in most cases) and justification (in all cases) are irreducibly normative issues. ${ }^{39}$

Hence, burdens and standards of proof, insofar as they concern the establishment of material facts, will only bring the analysis so far. ${ }^{40}$ Nonetheless, what limitations clauses could be distributing are burdens of demonstration — or argumentation - in relation to both the infringement and the justification issues. Again, these issues are normative ones and therefore have little to do with empirical, material-factsconcerned notions of burden and standard of proof. But call it what you will — burden of 'demonstration,' 'argument,' etc.- - the notion of burden can still usefully apply when it comes to the establishment of normative (as opposed to factual) propositions. ${ }^{41}$ As concerns the notion of standard (of demonstration, of argument), as we shall see, it is slightly trickier.

One other difficulty which arises at this point is that if we take the issues of infringement and justification (and thus the attribution of value) to be moral as well as legal issues, then the standard view is that the court takes judicial notice of these norms and is deemed to know them. It would then seem to follow that although the parties may provide suggestions as to how to solve the infringement and justification issues, the failure of any of them to demonstrate to the court how to get to some conclusion should not prevent it from reaching that conclusion itself. In other words, following the judicial notice rule to its logical conclusion, it would seem that parties to a legal case never really have argumentative burdens or burdens of legal demonstration. Courts are deemed to know the law, which includes the fundamental attribution of value in the constitutional context, and therefore can presumably articulate a legal reasoning or attribution of value that has not been put forward by a party. So a plaintiff will, of course, make some arguments as to what the particular infringement is in relation to the rules of infringement established by the Court, or as to fundamental attributions of value, but presumably the Court could (and, in principle, ought to if the party fails to do so) do all of this by itself because it is deemed to know the law. The same goes for justification: the government will put some arguments forward as to justification, but it seems that the Court could also do it by itself.. ${ }^{42}$ This is a matter of law (and in the constitutional rights context, of morality) and not of fact.

Yet, this is a very academic way of describing constitutional litigation: in practice, it may well happen that one of the parties provides apparently insufficient normative

39. Not unlike issues such as whether a person acted negligently or reasonably in a civil liability case.

40. A similar point is made by Danielle Pinard in 'La promesse brisée de Oakes' in Tremblay \& Webber, supra note 19, 131, esp. at 149-50, 152.

41. See Giovanni Sartor, 'Defeasibility in Legal Reasoning' [Sartor] in Zenon Bankowski, Ian White \& Ulrike Hahn, eds., Informatics and the Foundations of Legal Reasoning (Boston, MA: Kluwer 1995) [Bankowski et al.] 119 at 122.

42. Clearly, a court reaching a decision on legal grounds not discussed by the parties may cause problems in terms of the adversarial principle which underlies our procedural regime. 
arguments for its position and that these arguments will not be supplemented by the court despite the fact that other more convincing arguments exist. In such a case, if we do recognize the existence of burdens of demonstration/argumentation, the party bearing that burden would lose. Moreover, these burden-rules could be helpful in cases of moral uncertainty, as they would come in to break a tie in argument. Hence, if for any reason it is unclear or uncertain that there is an infringement, the plaintiff should lose. And if it is unclear or uncertain that some infringement is justified, then the government should lose. This leads to asking whether there are ever "ties" or indeterminacies when it comes to moral/legal issues. Now, the answer to that question is to be found in the intricacies of basic legal theory and metaethics. For my part, I shall stay clear of such intricacies and will simply assume that there are indeed such indeterminacies, and thus assume that burdens of justification could be useful because they move things along and enable final and authoritative decision-making in such cases.

In sum, in the constitutional rights context, it seems that burden-rules may be helpful either to allocate responsibility for argumentative insufficiency or to break moral uncertainty, both of which can occur either at the infringement or at the justification stage. And at the infringement stage, it appears generally appropriate to let the burden of insufficiency/uncertainty fall on the plaintiff. ${ }^{43}$ As we shall see, the basic (obviously state-favourable) presumption is that legislation adopted by the state is constitutional, and thus anyone challenging the validity of legislation has the burden of showing that it is indeed invalid. At the justification stage, however, it may appear more appropriate to let the burden of insufficiency/uncertainty fall on the state. At that stage the presumption is that some right has been violated, some unjustified action has occurred, and the government is in the best position to show that all things considered this infringement of rights-provision related values is justified. But note that moral indeterminacy as to the justification of a given legal norm could also be resolved through other tie-breaking devices. For instance, a judge could decide to let the state's norm be in order to promote the authority of the government, and another could decide to invalidate it to put it into question. Hence, depending on a judge's moral-political leanings (i.e., his fundamental attribution of value), a presumption for or against the government/the individual could be consistently applied in cases of uncertainty (or incommensurability). This leads to a discussion of (normative) presumptions.

\section{B. Presumptions}

As with the notion of burden, in the legal context we generally think of presumptions in relation to material facts. For instance, showing that a letter has been mailed could be the basis for a legal presumption as to the addressee's knowledge of the contents of that letter. But, again as with the notion of burden, the notion of presumption can properly apply to normative propositions as well as to material facts.

43. This may not quite be the case with respect to so-called qualified rights (e.g., sections 7 and 8 of the Canadian Charter). 
For instance, showing the infringement of the conditions associated with a rightprovision seems to work as a rebuttable presumption that the State has acted unjustifiably (or that the right has been violated).

Joseph Raz usefully distinguishes between three senses of presumptions. First, he says, '[a] presumption of ...' is sometimes used to indicate that the burden of adducing evidence and marshalling arguments is on those who challenge the presumed view. ${ }^{34}$ The second sense of presumption 'acts to sever the normal connection between belief and action' when there is a practical need to act in the absence of sufficient reasons for belief. ${ }^{45}$ So if a next of kin has no news of a person for a fixed number of years, the law presumes that that person is dead, even though having no news is not in and of itself sufficient evidence to believe that someone is actually dead. Raz then usefully points out that these first two senses of 'presumption' are the main ones used in moral, political and legal contexts and that they stem from 'practical and institutional concerns which require deviation from the (otherwise) normal course of rational inquiry and action. ${ }^{96}$ It should be remembered at this point that in the adversarial legal context, argumentative order and finality are concerns of particular importance. Finally, Raz distinguishes a third sense of presumption as referring to "the existence of an unrefuted reason for believing something which is just enough to justify the belief, though its weight is such that suspension of belief is also rational in the circumstances. ${ }^{47}$ Thus, a given presumption cannot take on the senses two and three at the same time, as these are mutually exclusive. But it could take either senses one and two or one and three at the same time, since the attribution of burden is usually dependent on the prior creation of the presumption, which is itself a function of the underlying reasons for taking a fact as established in the absence of uncontroversially justified belief in the existence of this fact.

As hinted at earlier, in the constitutional rights context, we seem to begin with one basic presumption, which is that government measures do not violate rights (or impinge on right-provisions related interests unjustifiably). Call this the basic no-violation/no unjustified limit presumption. It is a presumption in the first sense mentioned by Raz: the burden of adducing evidence and marshalling arguments in favour of a violation/unjustified limit is on plaintiffs. If a plaintiff can show that conditions associated with the infringement of a right-provision are met, however, she has met her burden and a second presumption is triggered: call this the violation or unjustified limit presumption. This presumption is, I believe, a presumption in the first and third senses set out by Raz. The conditions associated with a right-provision infringement entail the existence of a so far (formally) unrefuted reason which is just enough for believing that there has been a violation/unjustified limit, though the weight of that reason is such that suspension of belief would also be rational in the circumstances (although whether one should

44. Raz, supra note 34 at 8 . Raz acknowledges an intellectual debt to Edna Ullman-Margalit for this part of his discussion. See E. Ulmann-Margalit, 'On Presumptions' (1983) 80 J. Phil. 143.

45. Ibid. at 10 .

46. Ibid. at 11 .

47. Ibid. 
believe that there has been an unjustified violation or suspend belief may well depend on the right-provision at issue)..$^{48}$

Finally, the violation/unjustified limit presumption can be rebutted by arguments which show that all things considered the state's law is justified, viz., by arguments that meet the proportionality test. This actually means that the violation/unjustified limit presumption will be rebutted if the state can show that in fact there is no violation/the limit is justified. That is its burden. But according to what standard of demonstration, it may be asked? Is there a particular standard which has to be met for justification? Not really, it seems. Or, rather, I should say that that standard will be fixed by normative ethics or practical reason, which concern which actions are morally or rationally justified and which not, and according to what criteria. In other words, the standard is moral justification itself. It would however be foolish to start arguing for (or pick) one particular moral theory over another here.

\section{Defeasibility}

Burdens and presumptions are closely associated with the prima facie/defeasible quality of propositions in legal-judicial reasoning. ${ }^{49}$ Hence, it could be said that the constitutional rights decision-making process makes use of burdens and presumptions and involves prima facie conclusions which are characterized by their defeasibility. Prima facie truth-value or justification is so closely associated with defeasibility that it is of no great consequence for our purposes to only focus on the latter. Simply put, a proposition (either strictly factual or normative) is defeasible (i.e., prima facie true, or prima facie justified) if it can be defeated when further considerations are put forward. ${ }^{50}$ Legal rules concerned with judicial decision-making often provide that in order for the court to reach a certain conclusion (like the existence of a right) only a limited set of conditions has to be met, but that this conclusion could be defeated if some other conditions were met. Therefore, defeasibility is ubiquitous within the judicial decision-making process and this ubiquity can be explained by the pragmatic advantages offered by defeasibility for that process. ${ }^{51}$ Notably, defeasibility effects a division of labour in the search for knowledge and arguments. It may therefore stimulate such a search in a party who is afforded the possibility of defeating an unwanted legal conclusion. ${ }^{52}$ Ideally, that division should be equitable and be based on moral considerations. Also, that division of

48. Again, compare where one stands after the first step when applying s. 2(b), on the one hand, and s. 7 , on the other.

49. For instance, see the discussion of defeasibility and onus of proof in G.P. Baker, 'Defeasibility and Meaning' in P.M.S. Hacker \& J. Raz, Law, Morality, and Society: Essays in Honour of H.L.A. Hart (Oxford: Clarendon Press, 1977) 26 at 32-33, 45.

50. John Finnis 'defeasible' in Ted Honderich, ed., The Oxford Companion to Philosophy (New Edition) (Oxford: Oxford University Press, 2005) 194. The origin of the notion is often attributed to H.L.A. Hart, who introduced it in 'The Ascription of Responsibility and Rights' in Antony Flew, ed., Logic and Language (First Series) (Oxford: Basil Blackwell, 1963) 145 at 148, 150, 160-62.

51. See Neil MacCormick, 'Defeasibility in Law and Logic' in Bankowski et al., supra note 41, 99 at $104,106$.

52. See Sartor, supra note 41 at $119,142$. 
labour, when coupled with attributions of burdens and presumptions, enables the reaching of final authoritative decisions, even in the face of informational insufficiency or uncertainty. This is crucial, since authoritative finality is one very important aspect of judicial decision-making.

Following Sartor, one way to further explain defeasibility is to start with a basic logical conception of the legal norm as a conditional statement. Hence, a legal norm can logically be conceived as subordinating a legal conclusion (a consequent) to the ascertainment of a set of conditions (a total legal antecedent). We can thus conceive the antecedent of a complete norm as implying its consequent when all its conditions are shown to be satisfied. But, although this conception of the legal norm may be logically adequate, it does not quite capture the way in which legal norms are usually operated by judges in the derivation of legal conclusions. In the context of a legal dispute, judges are asked to determine authoritatively what the legal situation is once and for all. Hence, their role could be described as determining once and for all whether the conditions of the total legal antecedent of a legal norm are fulfilled or not. And in a sense, this is what they do, as the ascertainment of a legal effect requires applying the appropriate legal norms to the facts of the case. That said, however, for the sake of decisional finality, particular rules of judicial decisionmaking specify that the ascertainment of all logically required elements of a total legal condition is not necessary for a judge to be justified in reaching the associated legal conclusion. Rather, a judge ought to deem the total condition fulfilled, and therefore the associated conclusion ascertained, whenever: (1) certain elements of that condition (the 'elements to be proved' or probanda) are ascertained; and (2) the complements of the other elements of the condition (the 'elements not to be refuted' or non-refutanda) are not ascertained. If the non-refutanda are ascertained/refuted, however, the conclusion is defeated. Thus, the ascertainment of the probanda creates a presumption as to the validity of the associated legal conclusion, but that presumption can be rebutted by establishing the existence of nonrefutanda. Or, in still other words, the ascertainment of probanda render the legal conclusion valid prima facie, but that conclusion can be invalidated by the ascertainment of the non-refutanda. ${ }^{53}$

Note, however, that the logical distinction between probanda and non-refutanda is often not clearly delineated by legal provisions. The law will sometimes hint at the distinction through the creation of general rules and exceptions, through rules concerned with burden-distribution, or through rules establishing legal presumptions $^{54}$ (here again the conceptual links between burdens, presumptions and defeasibility become transparent). Therefore, in many cases, it will be up to interpreters, relying on interpretive tools, to translate these hints into defeasible normative

53. Ibid. at 119-21. Note that the negative literal NOT A, e.g., ' $x$ did not kill $y$ '' is the complement of the positive literal A, i.e., 'x killed y.' Note also that the distinction between probanda and non-refutanda applies to all the elements specified in a norm antecedent. It does not only apply to facts to be proved through empirical evidence, but also to elements which express legal qualifications; see also Juan Carlos Bayón, 'Why Is Legal Reasoning Defeasible' (2002) 2 Dirrito \& Questioni Pubbliche 1 at 3-5.

54. Sartor, ibid. at 123-24. 
structures. ${ }^{55}$ For instance, the law's use of terms such as 'unless', 'save that', 'except that', etc often tend to signal the presence of an exception, the conditions of which have to be proved by the defendant. A teleological analysis can also help establishing which elements among those conditioning the legal effect represent the substantial justification of that effect, and thereby help establishing the rule/probanda. ${ }^{56}$ Clearly, an argument put forward in favour of a norm being the rule or the exception will be all the more persuasive when textual and teleological arguments dovetail. Indeed, as mentioned earlier, defeasible rules attributing burdens or establishing presumptions should ultimately reflect evaluative considerations relating to fairness and pragmatics. ${ }^{57}$

For instance, in Oakes, the Supreme Court of Canada has construed the presence of the words 'subject only' in s. 1 as a textual hint that a justified infringement was the exception and an unjustified one/rights-protection the rule. It also used a teleological argument to conclude that the 'protection of rights,' through the conditions imposed by right-provisions, constituted the substantial justification of the effect. In other words, Oakes conceived a justified infringement as an exception to the general rule of unjustified infringement, and thus put the onus of showing justification on the state's shoulders ${ }^{58}$ thereby characterizing absence of justification as a fact 'not to be proved'/to be refuted-as a non-refutanda. This is perfectly understandable, since it would have been difficult for the court, given the wording of s. 1 and the nature of Charter — claiming to protect individuals' rights against unwarranted infringements by the government-, to construe that provision otherwise.

Also, while the application of a general norm may be limited by specificallyworded exceptions, it will sometimes be limited by very general and indeterminate provisions. This can be at least partly explained by the fact that for many norms it would clearly be impractical, if not impossible, to provide an exhaustive specification of all non-refutanda. This would presuppose the exact identification of all circumstances capable of rendering legally unacceptable, in any future case whatever, the legal solution provided by the general rule. ${ }^{59}$ For example, the exception to rights-protection provided by s. 1 of the Canadian Charter is as broad as they come, as it states that there will be no remedy when a limit to a right is reasonable and demonstrably justified in a free and democratic society. Obviously, this exception to the rule of rights-protection had to be expressed broadly: section 1 is the sole exception provision for all of the Charter's right-provisions, which are meant to protect a vast array of considerations. Therefore, once the choice of a single limitations provision had been made, the exceptions to protection could not be spelled out very specifically by that provision.

55. Ibid. at 137-39.

56. Ibid. at 125 .

57. Ibid. at 122-23.

58. Ibid. at 128, 130. Now, as to the relation between probanda and non-refutanda and the allocation of burdens of proof, typically, the complaining party is saddled with the burden of proving the probanda and the defendant with the burden of proving the (complement of) non-refutanda. Hence, by determining which elements are probanda and which are non-refutanda, and by allocating burdens of proof, the law determines which party bears the risks of non-ascertainment. 59. Ibid. at 139-41, 143 . 
Hence, in light of the foregoing discussion, the total antecedent of a constitutional rights-related norm can roughly be formalized as: 'conditions $\mathrm{I}_{1}, \ldots \mathrm{I}_{\mathrm{n}}$, associated with a given right-provision' + 'conditions $\mathrm{W}_{1}, \ldots \mathrm{W}_{\mathrm{n}}$, associated with 'government action not being justified'. A judge can thus consider all the elements of the total legal antecedent of the constitutional norm to be ascertained if (1) the conditions (I) associated with the infringement of a right-provision are ascertained and (2) the complements of the conditions (W) associated with 'the government's action is not justified' i.e., 'conditions associated with 'the government action is justified'. are not ascertained. If that is the case, a legal effect (i.e., a remedy) follows.

\section{In Praise of Two-Step Methodologies}

A few things should be put to rest. First, the infringement of the normative conditions flowing from a right-provision does not amount to the violation of anything except those very conditions. Quite clearly, it may properly be said that such an infringement amounts to a prima facie violation of a right or creates a (defeasible) presumption of violation. ${ }^{60}$ It may perhaps also be the case that such an infringement amounts in every case to the infringement of a right in the sense favoured by deontological normative theories. This hypothesis remains to be examined, but even then, the first step of the constitutional method would not consist in directly determining if a deontological right has been infringed. It would constitute an indirect, more formal, method for that determination. Be that as it may, it is only once a court has gone through the second step that we shall know whether it has been decided that a right has been violated or not.

A constitutional rights problem can properly be described as involving the determination of whether, in the end, all things considered, a right has been violated, i.e., whether the state has violated a duty connected to the protection of an individual interest, i.e., whether the state's action was justified or not. ${ }^{61}$ The two-step methodology consistently applied in constitutional rights cases may thus seem like a complicated way of answering these simple questions. It may then be tempting asked "why not simply cut to the chase and answer that question directly, in one single step?'. The most direct answer is, 'Because you cannot'. A constitutional rights question is a practical reasoning question, and it involves comparing and evaluating various competing considerations. More specifically, it involves situations in which individual interests deemed important are being infringed by state action. And it has to be determined whether these negative aspects of the state's actions are outweighed by its positive aspects (i.e., whether the action is justified all things considered). Such an exercise necessarily involves at least two intellectual steps: (1) determining what the negative aspects are and (2) determining what the positive

60. Or to what Joseph Raz refers to as 'a general non-relativized ought statement,' which 'usually means no more than that there is a reason for such action.' Joseph Raz, 'Introduction' in Joseph Raz, ed., Practical Reasoning (Oxford: Oxford University Press, 1978) 1 at 14.

61. Hence this leads us to Raz's conception of rights, according to which " ' $\mathrm{X}$ has a right' if and only if ... other things being equal, an aspect of X's well-being (his interest) is a sufficient reason for holding some other person(s) to be under a duty"; Raz, supra note 34 at 166. 
aspects are (or vice-versa), and then evaluating their respective weight. In short, in such a deliberative context, balancing is inevitable.

Another answer to the, 'why not just one step?' question would be that, because the issue arises before a public institution, which needs to provide authoritative final answers, it becomes necessary to formalize the reasoning and to make it understandable to those who will have to participate in the process. Because the documents are rights-documents (and not duties or justification documents), the reasoning starts with right-provision-infringement-associated negatives, and then moves on to the positives and full on balancing/justification. So 'rights' (which are really prima facie rights) take pride of place, but in the end, the question is whether state action which touches upon certain individual interests is justified or not. Or, put differently, whether the State has a duty not to act in that particular way.

\section{Conclusion}

The point of this article was to defend two-step proportionality balancing methodology in constitutional-rights decision-making. It has been argued that the arguments against the two-steps and the proportionality elements of that methodology remain unconvincing. It is very unlikely that the fragmentation of the reasoning and proportionality-discourse have any significant moral consequences. On the other hand, in the context of public legal argumentation and decision-making, they play an important role as structuring and heuristic devices for moral-political reasoning. ${ }^{62}$ Therefore, the balance of reasons clearly favours the maintenance of the method.

62. Pace K. Moller, 'Balancing and the Structure of Constitutional Rights' (2007) 5 Int'l. J. Const. L. 453 at 464-65, this is far from being uninteresting. For a similar outlook on TSPB see Stone Sweet \& Mathews Global Constitutionalism, supra note 1 at 80-97; Alec Stone Sweet \& Jud Mathews, 'All Things in Proportion: American Rights Doctrine and the Problem of Balancing' (March 12, 2010), available at SSRN: at 80, 87 [Emory L.J., forthcoming]. Perhaps Webber would not reject some form of rejoinder, however, since he writes, 'If proponents of the principle of proportionality openly maintained that a proportionality analysis merely identifies the skeleton according to which an argument should proceed, they would avoid [many of his] criticisms, but only to weaken the place of the principle of proportionality in constitutional theory and practice.' Webber Cult, supra note 2 at 193. 